\title{
Failure Analysis of Rheocast Cylinder Head Covers of Hypereutectic Al-Si Alloys
}

\author{
Jian Feng (1)
}

Submitted: 6 December 2020/Accepted: 8 December 2020/Published online: 22 December 2020

(C) The Author(s) 2020

\begin{abstract}
The purpose of the present study is to determine the cause of failures of semisolid rheocast cylinder head covers of hypereutectic modified LM30 alloys. The covers, manufactured by rheocasting, a process that consists of the incorporation and homogeneous distribution of the reinforcements in semisolid metal (SSM) before die casting, were shot-peened after heat treatment to increase the fatigue resistance. However, these engine components failed during operation after a short service time. The major flaws were located by radiography. The microstructure was controlled by metallography. Significant interactions between shot peening and surface/subsurface contaminants were identified by surface morphology and fractography. The fatigue properties of hypereutectic alloys were investigated by a high-frequency vibrophore. It was identified that the failure was related to the cleanliness of SSM as well as the rheocasting process. Recommendations were given to prevent the recurrence of similar failures.
\end{abstract}

Keywords Aluminum casting - Rheocasting · Fractography · Fatigue - Failure analysis - Shot peening · Engine

\section{Introduction}

Modern combustion engines work under growing thermomechanical loads due to the increasing demand for power and efficiency. The cylinder head cover, conveying air and

\footnotetext{
J. Feng $(\bowtie)$

Centre of Materials Engineering, Heilbronn University, Max-

Planck-Str. 39, 74081 Heilbronn, Germany

e-mail: jian.feng@web.de; jian.feng@hs-heilbronn.de
}

gasoline to the combustion chamber as a cover for the cylinders, must remain strong and rigid to distribute the gas forces as uniformly as possible throughout the entire engine block. To resist the high combustion pressure, the cylinder head cover is produced as a monolithic block, whereby generally Al-Si alloys are used. Lightweight hypereutectic $\mathrm{Al}-\mathrm{Si}$ alloys (> $12.6 \mathrm{wt} . \% \mathrm{Si}$ ) are, in reality, in situ metal matrix composites (MMCs) of hard primary $\mathrm{Si}$ crystals disbursed throughout a ductile $\alpha$-Al matrix and brittle eutectic regions, and thus have been used in applications where excellent dimensional stability, high wear and strength resistance, as well as low thermal expansion, are required. To maintain favorable machinability concurrently, the primary $\mathrm{Si}$ crystals of hypereutectic Al-Si alloys should be reasonably small-dimensioned and uniformly distributed throughout a cast matrix, which can be achieved by semisolid metal (SSM) rheocasting [1-3].

Rheocasting involves the preparation of SSM slurry from the liquid phase by stirring the alloy during solidification and transferring directly into a high-pressure die for component shaping. Viscous and non-turbulent SSM slurry fills thin cast sections easily. Rheocasting restricts ideally the solidification shrinkage and pore formation in the net or near-net shape products. It has low input materials costs and provides greatly extended tool life in comparison with conventional high-pressure die casting. However, rheocasting of hypereutectic Al-Si alloys is much more complex in terms of casting and processing technology than in the case of using commercial hypoeutectic alloys.

In the present case, a complete batch of cylinder head covers in modified BS LM30 (Al-17Si-3Cu-Fe-Mg) alloys were shot-peened after rheocasting and $\mathrm{T} 5$ heat treatment, as shown in Fig. 1. Oil leakage was observed on several of them during operation after a short service time, whereas 
the seals remained securely tight. On the failed parts no visible damage was found. The present study determines the causes of the defects that led to the failure of the cylinder head covers. It is based on chemical analysis, radiography, metallography, surface morphology, fatigue analysis and fractography of the failed parts. Possible solutions for future production are suggested to prevent or reduce the initiation of defects that occurred during the rheocasting and processing of cylinder head covers.

\section{Material Testing Results}

\section{Chemical Analysis}

As shown in Table 1, the chemical composition of the failed cylinder head covers, determined by glow discharge optical emission spectroscopy (GDOES, Spectruma GDA750) and X-ray fluorescence spectrometry (XRF, Olympus Innov-X), confirmed that the alloy investigated met the original design specifications. As compared to the
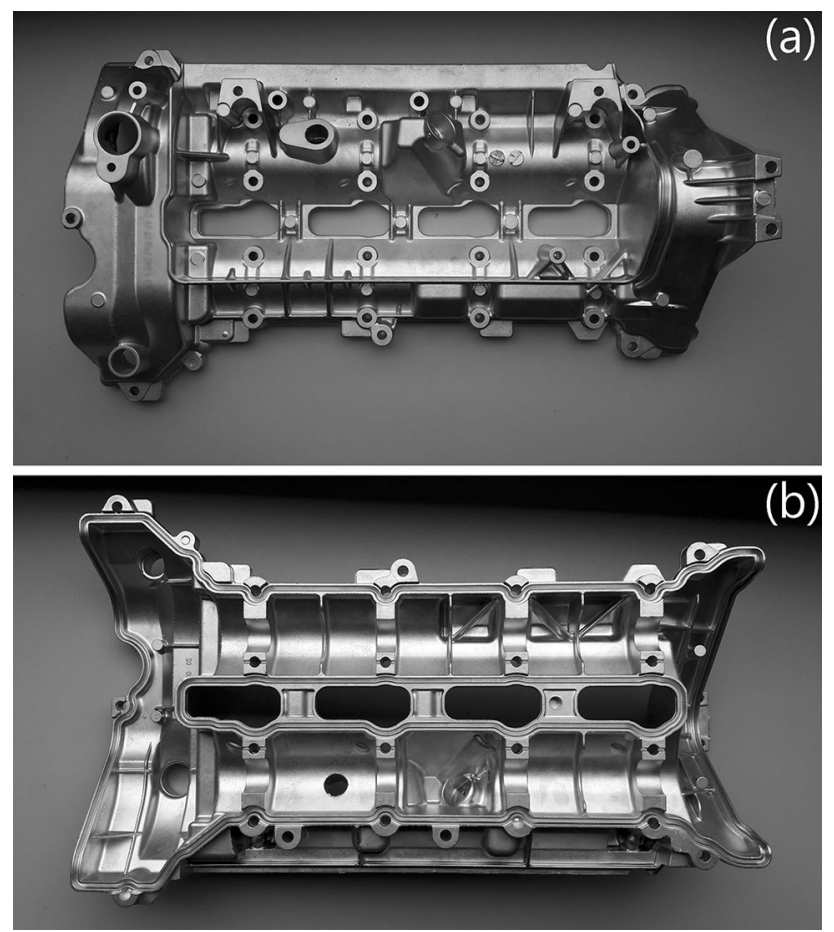

Fig. 1 A SSM rheocast cylinder head cover from the failed batch

Table 1 Chemical composition of SSM rheocast cylinder head covers investigated (in wt\%)

\begin{tabular}{lcccccccc}
\hline $\mathrm{Si}$ & $\mathrm{Fe}$ & $\mathrm{Cu}$ & $\mathrm{Mn}$ & $\mathrm{Mg}$ & $\mathrm{Ni}$ & $\mathrm{Zn}$ & Others total & $\mathrm{Al}$ \\
\hline 16.9 & 1.0 & 2.8 & 0.28 & 0.45 & 0.08 & 0.87 & $<0.15$ & Bal.
\end{tabular}

conventional hypereutectic Al-Si alloys such as BS LM30, AA 390.0, or MAHLE M126, the alloy investigated shows a lower $\mathrm{Cu}$, but a higher $\mathrm{Zn}$ content. The $\mathrm{Cu}$ content was kept below $3.0 \mathrm{wt} . \%$ to limit the precipitation effect of $\theta$ $\mathrm{Al}_{2} \mathrm{Cu}$ and reduce the casting defects. $\mathrm{Cu}$ imparts heat treatability to castings and remarkably enhances mechanical properties; however, high $\mathrm{Cu}$ content may cause the formation of micropores, which leads to deterioration of castability [4]. The reduction in the $\mathrm{Cu}$ content was replaced by the $\mathrm{Zn}$ addition in the present alloy. Apart from dissolution in $\alpha-\mathrm{Al}$ and formation of hardening phases, $\mathrm{Zn}$ disorders the other precipitating complexes effectively. The combined addition of $\mathrm{Zn}$ and $\mathrm{Cu} / \mathrm{Mg}$ improves the agehardening response and leads to higher peak hardness at shorter aging times.

\section{Radiographic Testing}

To locate the major flaws, X-ray radiography testing (RT, AMICA 401) was employed. A radiographic film was used as a detector. A sufficient change in density/thickness of parts can produce a change in the intensity of the transmitted radiation beam. The change in the density will be then recorded on a radiographic film. Color-reversed X-ray radiographic images of the best and worst cases of SSM rheocast cylinder head covers are shown in Fig. 2a and b, respectively. After color reversal, the highlighted area in Fig. $2 b$ appears on the X-ray film much brighter than the

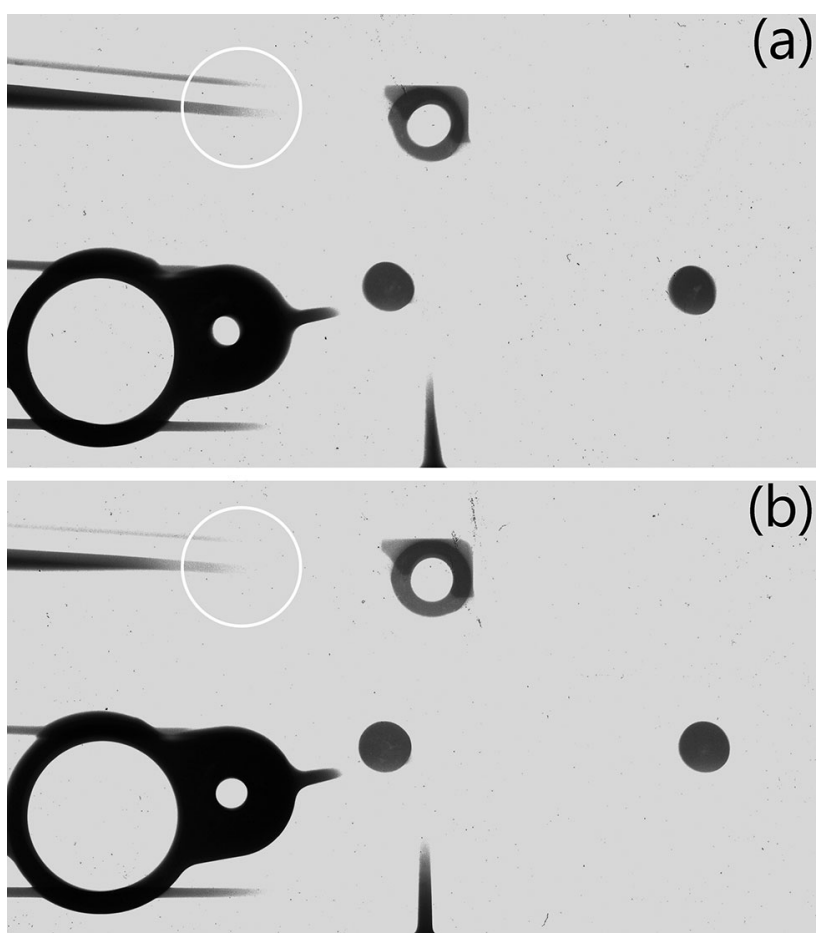

Fig. 2 Color-reversed X-ray radiographic images of failed SSM rheocast cylinder head covers: $\mathbf{a}$ the best and $\mathbf{b}$ the worst case 
same area in Fig. 2a, indicating that the area was less dense/thick. In this way, the major flaws that could be responsible for the failures were located.

\section{Metallography}

As shown in Fig. 3, particle-reinforced MMCs can be identified in the sectioned parts, which consists of polygonal primary Si particles with eutectic mixtures embedded in a ductile globular $\alpha$-Al matrix. Neither particle cracking nor significant interface defects were observed in MMCs, indicating that the lifetime of the failed part was short, and the load-carrying ability of the primary $\mathrm{Si}$ phase was not represented before the failure. The distribution of polygonal primary $\mathrm{Si}$ particles was largely uniform, and the average equivalent size of primary $\mathrm{Si}$ particles was $16 \pm 5 \mu \mathrm{m}$. The eutectic Si phase, fine and fibrous, coarsened along the solidification path extending from the surface to the center of the sectioned part. The amount of $\mathrm{Al}-\mathrm{Si}$ eutectic mixtures and the density of shrinkage porosity, which exhibits a tortuous morphology delineating the solidification structure, increased along the solidification path as well. The most significant shrinkage porosity about the centerline of sectioned parts and cracks (cold folds) along the eutectic regions are shown in Fig. 3a and c. Although rheocasting can potentially minimize these defects, the complex shapes of cylinder head covers mean that ideal conditions were not easily achieved and both types of defects could occur. Beyond reducing the effective load-bearing section area and affecting the fatigue crack growth rates, they may have a more active role in crack initiation.

It is shown in Fig. 4 the aspect ratio dependence of equivalent sizes of internal imperfections (cracks, defects, and inclusions) in failed SSM rheocast cylinder head covers. The equivalent size was calculated on un-etched sectioned parts by $\sqrt{\text { area }}$ in $\mu \mathrm{m}$, i.e., the square root of the projected area of an imperfection onto a plane perpendicular to the maximum principal stress [5]. Shrinkage porosity could be characterized by a relatively large equivalent size and a low aspect ratio, while spherical gas porosity by a relatively small dimension and a high aspect

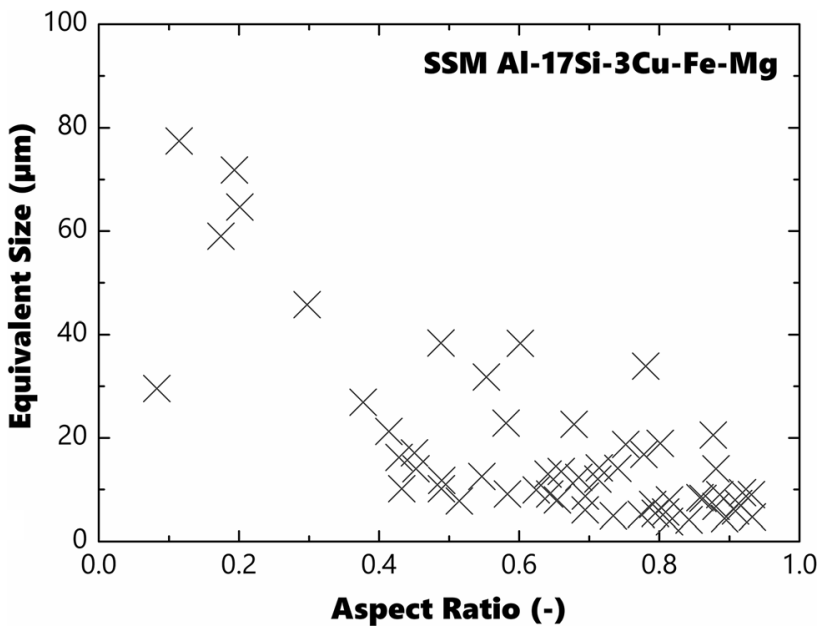

Fig. 4 The aspect ratio dependence of the equivalent size $\sqrt{\text { area }}$ of internal imperfections in failed SSM rheocast cylinder head covers
Fig. 3 The microstructure of the failed SSM rheocast cylinder head cover: (a) and (c) center regions of sectioned parts, A: primary $\mathrm{Si}, \mathrm{B}: \alpha-\mathrm{Al}, \mathrm{C}$ : eutectic mixtures; (b) and (d) outer regions of sectioned parts

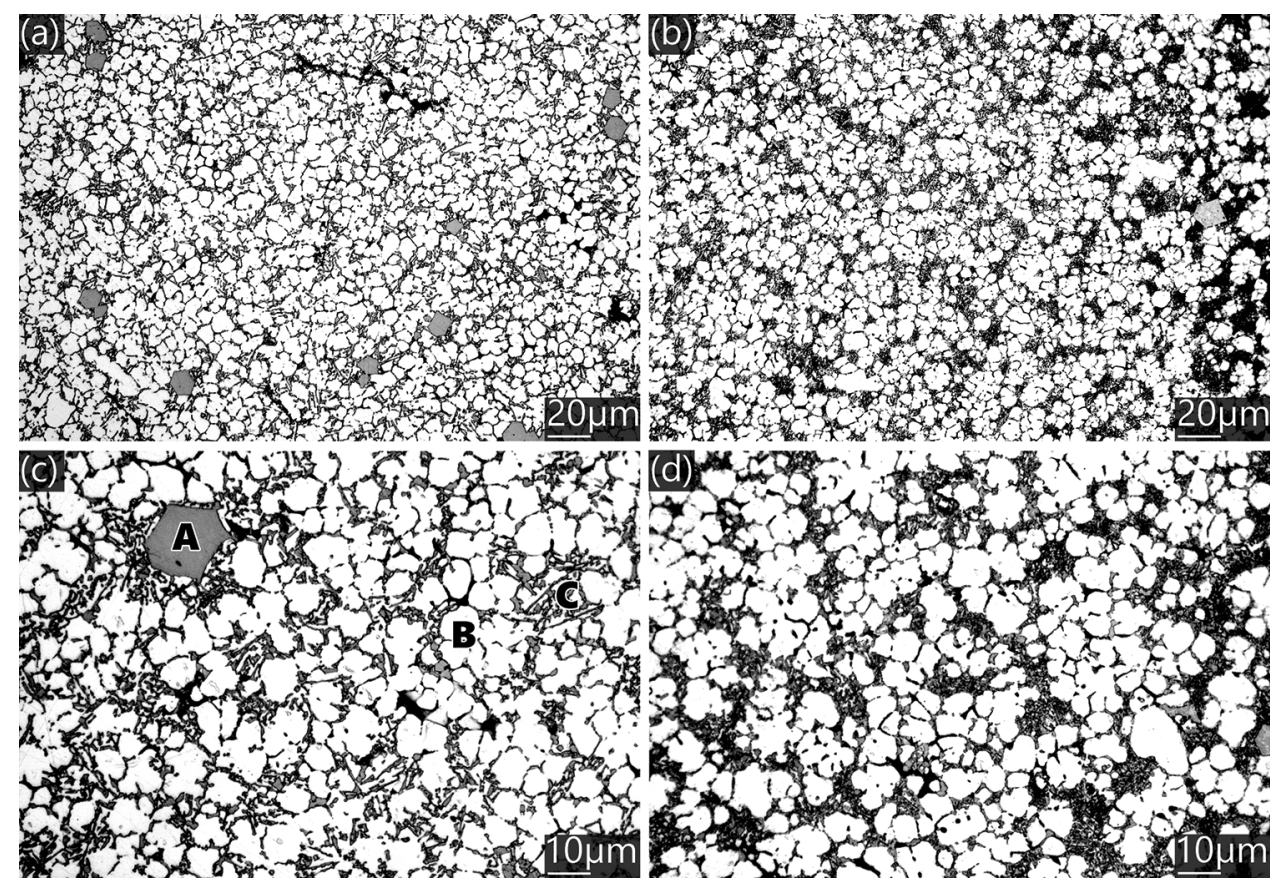


ratio. As shown in Fig. 4, significant shrinkage porosity can be identified, which could be detrimental to the thermomechanical fatigue resistance of the SSM rheocast cylinder head covers.

\section{Surface Morphology}

As shown in Fig. 5, significant surface cracking was observed on the defect area located by the radiography. The morphology of the cracking is different from the one induced by the thermomechanical fatigue. A microscopic, interconnected crack pattern (heat checking) of the thermomechanical fatigue can be either cell-type under a multi-axial loading or parallel-type in the case of uniaxial loading. The cracking in the present case is stepwise and the shot-peened pattern stretched thoroughly from the bottom to the top parts of the steps, indicating that the cracking could be induced by shot peening itself. Largedimensional $\mathrm{Al}_{4} \mathrm{C}_{3}$ contaminants, confirmed by electron diffraction spectroscopy (EDS, Bruker Quantax) investigations (Fig. 6), were observed on the shot-peened surface of the failed SSM rheocast cylinder head covers (Fig. 5c). The significant surface cracking could be tightly connected to these large-dimensional contaminants under severe plastic deformation (shot peening), especially in the case that the contaminants lay directly beneath the surface.
Fatigue

Fatigue testing was performed at $20^{\circ} \mathrm{C}$ ambient temperature by a high-frequency Zwick-Roell vibrophore on wirecut specimens. For the convenience of discussion, it is assumed that the alloy does have an apparent fatigue limit. As shown in Fig. 7, the apparent fatigue limit and the

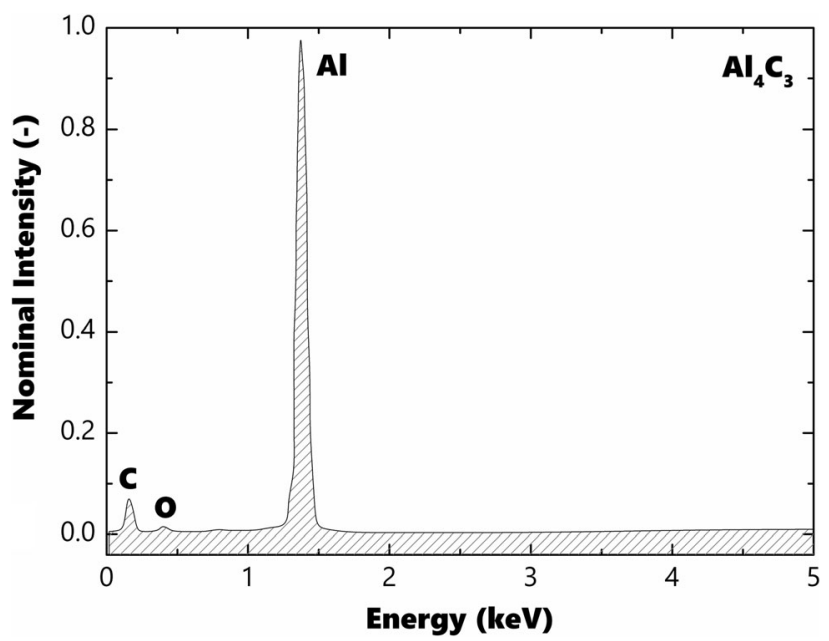

Fig. 6 EDS spectra in position $X$ of the contaminant shown in Fig. 5c
Fig. 5 Morphology of the cracked surface after shot peening on the failed SSM rheocast cylinder head covers. (a) SE and (b) BSE image of the surface crack, (c) SE image of a shot-peened contaminant, and (d) zoomed image of the highlighted area in (b)

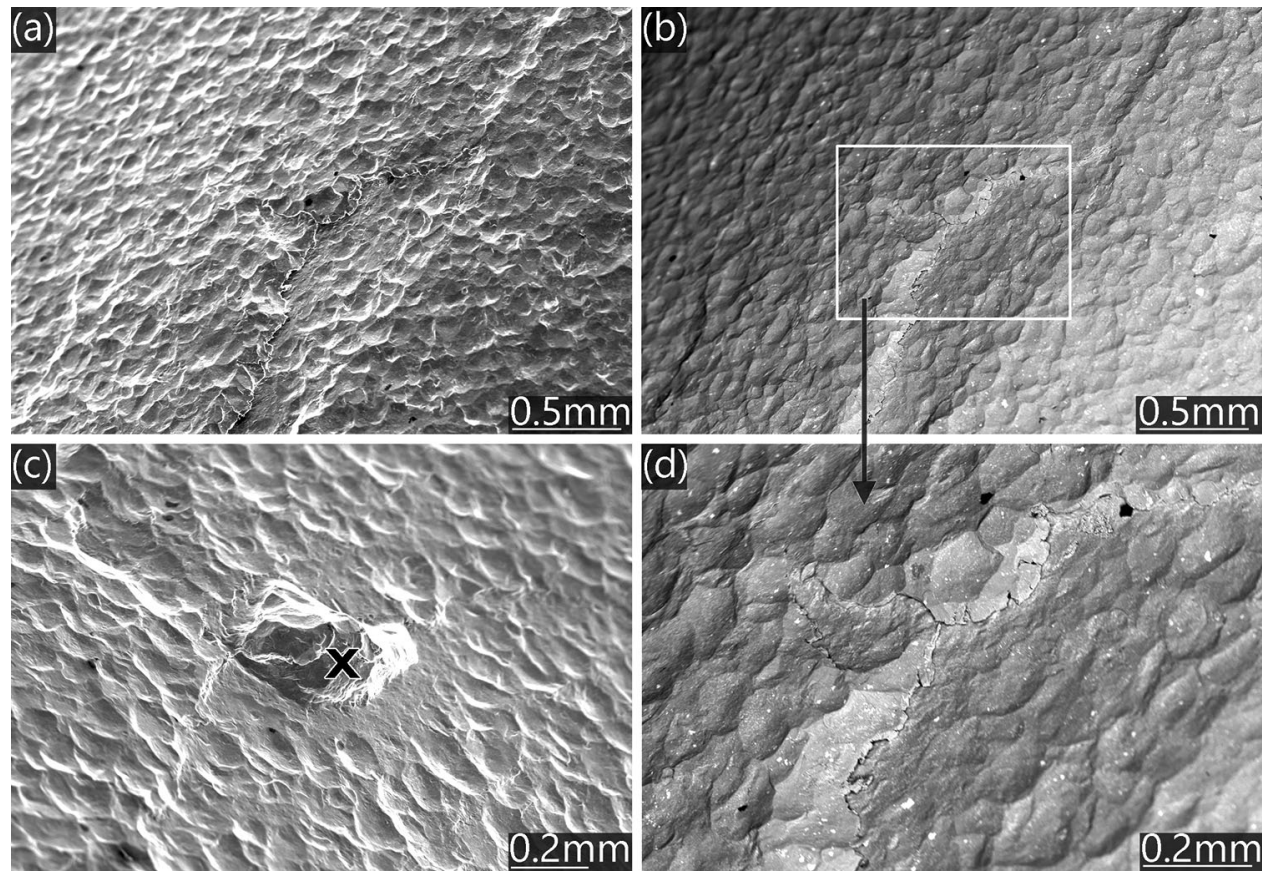


dashed curve representing the $50 \%$ probabilities of failure $(\mathrm{PoF})$ were estimated by the software FVA-Workbench 6.0. The obtained apparent fatigue limit of $78.2 \mathrm{MPa}(50 \%$ $\mathrm{PoF}$ ) is far lower than the designed one (dash-dot line) of approx. $110 \mathrm{MPa}(50 \% \mathrm{PoF})$ as anticipated. This value is also much lower than the fatigue limit of conventional BS LM30 alloys tested at the same temperature. Notably, there is considerable scatter in the results of the experimental S$\mathrm{N}$ curve.

\section{Fractography}

Fracture surfaces of the specimens after fatigue testing were investigated by scanning electron microscope (SEM, JEOL JSM 6150). As shown in Fig. 8, the failure at a

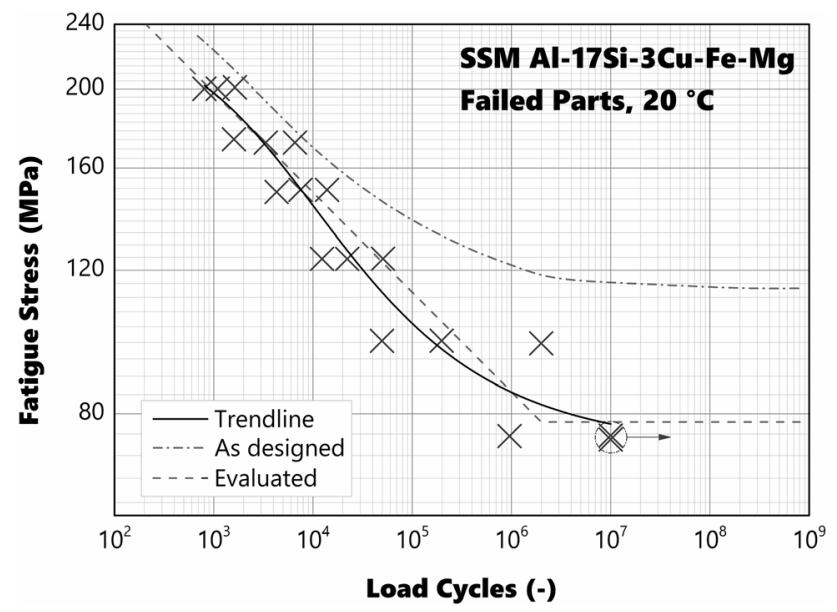

Fig. 7 S-N curve for hypereutectic Al-Si specimens cut from failed SSM rheocast cylinder head covers

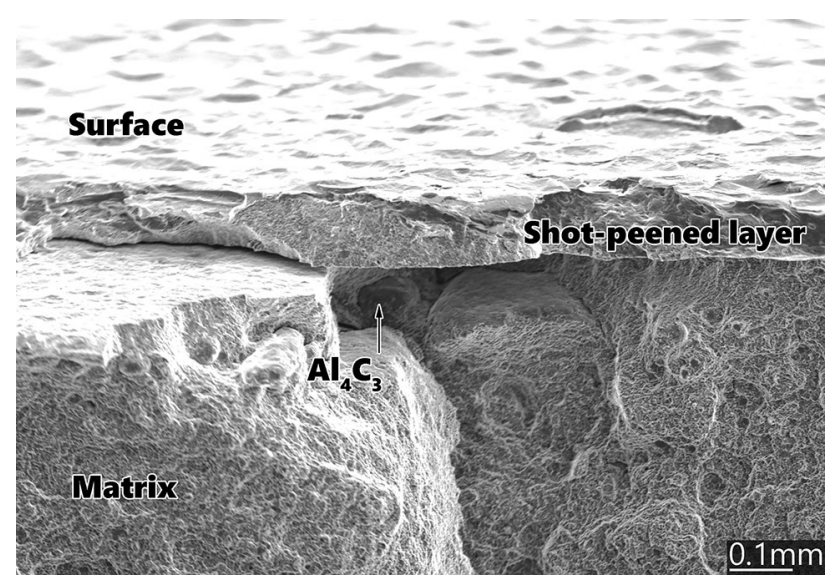

Fig. 8 Fractography of fatigue specimens cut from failed SSM rheocast cylinder head covers (fatigue stress $200 \mathrm{MPa}$ ) fatigue stress of $200 \mathrm{MPa}$ was initiated from a polyhedral $\mathrm{Al}_{4} \mathrm{C}_{3}$ inclusion beneath and in touch with the shot-peened layer. 3D matrix cracking radiated further into the deep of the matrix. Significant interface debonding was observed between the matrix and the shot-peened layer. The strong interactions between the hard inclusion and severe mechanical shot peening, along with the resulted unfavorable residual stress states, were responsible for the intense crack initiation, which explains the findings in the investigation of surface morphology (Fig. 5).

\section{Discussion}

The observed poor fatigue performance of the SSM rheocast cylinder head covers can be explained by the equivalent size $\sqrt{\text { area }}$ (see above) dependence of the fatigue limit in a wide range of engineering alloys, which can be represented by $\sigma_{w}^{n} \sqrt{\text { area }}=\eta_{i}$ [5]. Here $\sigma_{\mathrm{w}}$ is the fatigue limit, $n$ is a material-dependent index, and $\eta_{i}$ is the Vickers hardness relevant constant with $\eta_{1}<\eta_{2}<\eta_{3}$, where 1 implies surface contaminants, 2 contaminants in touch with a surface (subsurface), and 3 the internal imperfections, respectively. The surface and subsurface contaminants have the most detrimental effect on the fatigue resistance of the components [6].

In the present case, the surface and subsurface contaminants were identified to be aluminum carbides by EDS measurements. $\mathrm{Al}_{4} \mathrm{C}_{3}$ inclusions are very common contaminants found in aluminum coming from the electrolysis process [7] and are present in commercially pure aluminum ingot used to produce SSM. They may also occur from the stirring and/or degassing of a melt using a graphite impeller for a fairly long period at high temperatures [7]. The internal imperfections (cracks, pores, and inclusions) could be ascribed to the unfavorable cleanliness of SSM and inappropriate processing of rheocasting. In the present mass production by rheocasting, returns (scrap) were directly recycled in-house without going through chemical purification. Intensive stirring dispersed harmful oxide inclusion clusters and broke oxide films into fine inclusions. The porosity can be either directly or indirectly influenced by the SSM cleanliness. Die casters have found by experience directly that the porosity levels often increase when $100 \%$ returns are used constantly for a period without adequate treatment [8]. Indirectly, the fluidity of contaminated SSM decreased accordingly comparing to the normal one especially at lower temperatures [9]. The production of thin-wall casting parts is limited by the fluidity of SSM. To improve the fluidity, the pouring temperature should be correspondingly increased, which, however, simultaneously increased the likelihood of 
shrinkage pores. Affected by solidification shrinkage, the volume fraction of pores can increase (exponentially) from the surface to the center of the component [10], which matches with our observations.

\section{Conclusions and Recommendations}

Shot peening can significantly increase the ratio of initiation life to the propagation life of the engine parts in comparison with unpeened ones. However, it is not the case in the present study, where surface and/or subsurface contaminants were observed. Severe mechanical interactions between shot peening and contaminants relieved the crack initiation and led to significant surface cracking. This, together with the significant internal porosity, resulted in the poor fatigue performance of the SSM rheocast cylinder head covers and eventually the final failure. Given the above, to prevent the recurrence of similar failures, chemical purification of the returns must be strictly controlled and the cleanliness of SSM should be continuously improved. Thermal conditions of the die and the temperature of SSM, which are the major factors affecting the amount of shrinkage porosity for a given alloy composition and casting geometry, should be further optimized.

Acknowledgements The support from Steinbeis Foundation, Stuttgart is acknowledged.

Funding Open Access funding enabled and organized by Projekt DEAL.

Open Access This article is licensed under a Creative Commons Attribution 4.0 International License, which permits use, sharing, adaptation, distribution and reproduction in any medium or format, as long as you give appropriate credit to the original author(s) and the source, provide a link to the Creative Commons licence, and indicate if changes were made. The images or other third party material in this article are included in the article's Creative Commons licence, unless indicated otherwise in a credit line to the material. If material is not included in the article's Creative Commons licence and your intended use is not permitted by statutory regulation or exceeds the permitted use, you will need to obtain permission directly from the copyright holder. To view a copy of this licence, visit http://creativecommons. org/licenses/by/4.0/.

\section{References}

1. D.B. Spencer, R. Mehrabian, M.C. Flemings, Rheological behavior of $\mathrm{Sn}-15$ pet $\mathrm{Pb}$ in the crystallization range. Metall. Mater. Trans. B 3(7), 1925-1932 (1972)

2. M.C. Flemings, Behavior of metal alloys in the semisolid state. Metall. Trans. A 22(5), 957-981 (1991)

3. J. Jorstad, D. Apelian, Hypereutectic Al-Si alloys: practical casting considerations. Int. Metalcast. 3(3), 13-36 (2009)

4. M. Dash, M. Makhlouf, Effect of key alloying elements on the feeding characteristics of aluminum-silicon casting alloys. J. Light Met. 1(4), 251-265 (2001)

5. Y. Murakami, Metal fatigue: effects of small defects and nonmetallic inclusions (Elsevier, Amsterdam, 2002)

6. H.Z. Ye, An overview of the development of Al-Si-Alloy based material for engine applications. J. Mater. Eng. Perform. 12(3), 288-297 (2003)

7. L. Liu, F.H. Samuel, Assessment of melt cleanliness in A356.2 aluminum casting alloy using the porous disc filtration apparatus technique: Part I Inclusion measurements. J. Mater. Sci. 32(22), 5901-5925 (1997)

8. C. Tian, J. Law, J. van der Touw, M. Murray, J.Y. Yao, D. Graham, D. St, John, Effect of melt cleanliness on the formation of porosity defects in automotive aluminum high pressure die castings. J. Mater. Proc. Technol. 122(1), 82-93 (2002)

9. Y.-D. Kwon, Z.-H. Lee, The effect of grain refining and oxide inclusion on the fluidity of $\mathrm{Al}-45 \mathrm{Cu}-06 \mathrm{Mn}$ and $\mathrm{A} 356$ alloys. Mater. Sci. Eng., A 360(1), 372-376 (2003)

10. X.Y. Jiao, J. Wang, C.F. Liu, Z. Guo, J.Y. Wang, Z.M. Wang, J.M. Gao, S.M. Xiong, Influence of slow-shot speed on PSPs and porosity of AlSi17Cu2.5 alloy during high pressure die casting. J. Mater. Proc. Technol. 268, 63-69 (2019)

Publisher's Note Springer Nature remains neutral with regard to jurisdictional claims in published maps and institutional affiliations. 